\title{
ANALISIS RESISTANSI COIL KAWAT TEMBAGA TERHADAP PERUBAHAN SUHU SANGAT RENDAH SEBAGAI RANCANG DASAR PENGUKURAN SUHU RENDAH
}

\author{
Riswanto \\ Program Studi Pendidikan Fisika Universitas Muhammadiyah Metro \\ Email: rumbiariswan@gmail.com
}

\begin{abstract}
Abstrak
Resistansi sebuah kawat penghantar bergantung pada material bahan kawat. Kawat tembaga yang dibentuk menjadi bentuk coil merupakan bentuk yang efektif untuk menghasilkan nilai resistansi yang besar pada kawat. Resistansi kawat tembaga dipengaruhi pula oleh suhu lingkungan yang mengenainya. Coil kawat tembaga memiliki respon yang baik pada perubahan suhu yang rendah yang dihasilkan oleh nitrogen cair. Respon ini ditunjukan melalui nilai indeks determinasi $\mathrm{R}^{2}=0,999$ yang mendekati nilai 1 artinya perubahan suhu lingkungan direspon mendekati linier oleh perubahan tegangan. Hasil dapat dijadikan dasar bahwa kawat tembaga yang dibentuk menjadi coil tembaga dapat digunakan sebagai dasar perancangan pengukuran suhu rendah yang lebih murah.
\end{abstract}

Kata Kunci: Resistansi, Coil tembaga, Suhu rendah

\begin{abstract}
The resistance of a wire conductor depend of the wire material. Copper wire formed into a coil shape an effective form to produce a large resistance. Copper wire resistance influenced by temperature about it. Coil of copper wire has a good response at low temperature changes produced by liquid nitrogen. This response is shown by the index value determination $\left(R^{2}=0.999\right)$ which is close to the value 1 , that means changes in temperature approaching a linear response to changes in a voltage. The results can be used as a basis for the design of the low-temperature measurements cheaper
\end{abstract}

Keywords: Resistance, Coil of Copper wire, Low temperature berbagai produk canggih dan mutakhir.

\section{PENDAHULUAN}

Perkembangan ilmu pengetahuan dan teknologi kini banyak melahirkan
Hal ini dapat dibuktikan dengan banyaknya inovasi-inovasi yang telah dibuat manusia, dimulai dari yang paling sederhana hingga yang paling 
modern. Produk yang dilahirkan ditujukan untuk membantu dan memudahkan segala aktivitas manusia. Salah satu kemudahan yang diperoleh yaitu peran teknologi dalam membantu pengukuran besaran-besaran fisis. Suhu merupakan besaran fisis yang senantiasa berhubungan dengan aktivitas manusia. Pengukuran suhu banyak dibutuhkan dalam berbagai bidang misalkan bidang kedokteran, bidang perikanan, peternakan, dan sebagainya. Bentuk pengukuran suhu yang saat ini banyak dikembangkan adalah pengukuran suhu yang memanfaatkan sifat termometrik suatu zat atau dengan memanfatkan karakteristik dari sifat pemuaian zat.

Untuk sebuah konduktor dengan resistivitas $\rho$, kerapatan arus $\vec{J}$ di sebuah titik di mana medan listrik adalah $\vec{E}$ diberikan persamaan $\vec{E}=\rho \vec{J}$ yang dapat diilustrasikan melalui gambar 1 berikut

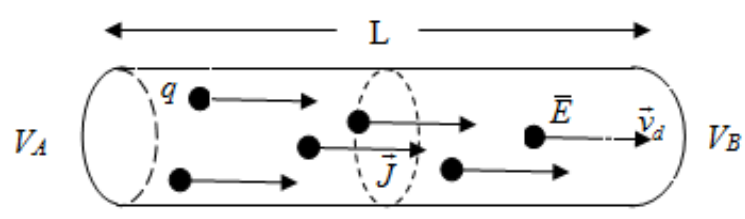

Gambar 1. Gerak arus dari $V_{A}$ menuju $V_{B}$
Jika kawat merupakan batang homogen maka potensial $V=\vec{E} \ell$. Dengan melakukan substitusi persamaan $\vec{E}=\rho \vec{J}$ maka diperoleh:

$$
V=\frac{\rho \ell}{A} I
$$

Persamaan 1 di atas memperlihatkan bahwa bila $\rho$ konstan, arus total $I$ itu sebanding dengan selisih potensial $V$. Rasio perbandingan $V$ terhadap $I$ dinamakan hambatan (resistansi)

$$
R=V / I
$$

Maka untuk mendapatkan hubungan hambatan terhadap hambatan jenis dapat dilakukan dengan substitusi nilai $V$ ke dalam persamaan 2 maka diperoleh persamaan $R$. Hambatan $\mathrm{R}$ kawat logam berbanding lurus dengan panjang $\mathrm{L}$ dan resistivitas kawat namun berbanding terbalik dengan luas penampang lintang A (Giancolli, 2001:70).

$$
R=\rho \frac{L}{A}
$$

Resistivitas sebuah konduktor logam hampir selalu bertambah dengan suhu yang semakin bertambah. Jika suhu bertambah, ion-ion konduktor akan 
bergetar dengan amplitudo yang besar, sehingga cenderung mengakibatkan tumbukan elektron (Muslim dan zahara, 2004:145). Pada jangkauan suhu yang kecil ( sampai $\pm 100^{\circ} \mathrm{C}$ ) secara aproksimasi hubungan resistivitas dengan suhu adalah

$$
\rho(T)=\rho_{0}\left[1+\alpha\left(T-T_{0}\right)\right]
$$

Karena nilai $\mathrm{R}$ sebanding dengan besarnya resistivitas, sehingga secara spesifik maka besarnya nilai $\mathrm{R}$ juga akan dipengaruhi oleh besarnya suhu. Hubungan ini memiliki analogi bentuk dengan persamaan 4 yaitu (Young and Freedman, 2001: 230)

$$
R(T)=R_{0}\left[1+\alpha\left(T-T_{0}\right)\right]
$$

Resistansi atau nilai hambatan dalam sebuah kawat penghantar dapat terpengaruh oleh perubahan suhu lingkungannya. Material murni seperti bahan platina memiliki respon resistansi yang baik terhadap perubahan suhu lingkungannya (A1 Hawari, 2011). Namun kendala yang dihadapi material platina memiliki harga yang relatif sangat mahal, sehingga dibutuhkan biaya yang lebih besar untuk merancang pengukuran suhu rendah.
Kawat tembaga merupakan bahan yang murah serta mudah didapat. Ketersediaan kawat tembaga yang cukup banyak mendorong peneliti untuk mencoba mengkaji karakteristik respon kawat tembaga terhadap perubahan suhu yang sangat rendah. Kawat ini dibentuk menjadi lilitan kawat tembaga yang disebut sebagai koil untuk memperbesar nilai resitansi kawat tembaga. Untuk mendapatkan suhu yang sangat rendah digunakan nitrogen cair. Karakter dari nitrogen cair yaitu akan mengembun pada suhu $196{ }^{0} \mathrm{C}$ pada tekanan atmosfer dan membeku pada suhu $-210{ }^{0} \mathrm{C}$. Dengan menggunakan nitrogen cair ini diharapkan akan mengubah suhu lingkungan yang terdeteksi menggunakan termokopel.

Pengembangan dari analisis karakteristik kepekaan resistansi coil tembaga dalam merespon perubahan suhu diharapkan dapat digunakan sebagai dasar untuk menghasilkan produk pengukuran suhu rendah. Tingkat kepekaan coil tembaga dalam merespon perubahan suhu nantinya menjadi tolak ukur kebaikan tingkat sensitivitas coil tembaga. 
Riswanto- Analisis Resistansi Kawat Coil Tembaga...

pengembangan ini diharapkan dapat bermuara kepada sebuah alat yang dapat melakukan pengukuran suhu rendah dengan karakter yang baik, murah dan mudah didapat.

Beberapa penelitian terkait dengan ide penelitian ini diantaranya yaitu Sebuah penelitian yang termuat dalam jurnal physics education oleh Galza (2012) membuat termometer suhu dengan memanfaatkan hambatan listrik. Penelitian menggunakan prinsip jembatan Wheatstone dengan menggunakan filamen lampu kecil yang biasa digunakan sebagai penerangan. Hasil yang diperoleh termometer ini memberikan tanggapan yang lebih cepat pada $10 \mathrm{~ms}$ sehingga ini baik digunakan untuk karakter pengukuran perubahan waktu suhu yang sangat cepat.

Meyers (1932) melakukan penelitian mengenai termometer dengan memanfaatkan hambatan filamen koil yang berbahan platinum. Platinum dibentuk dalam heliks ganda berupa kumparan dengan diameter $5 \mathrm{~mm}$ dan panjang $2 \mathrm{~cm}$ menghasilkan hambatan sebesar $25 \mathrm{ohm}$. Pengujian kinerja termometer menggunakan helium.

\section{METODE}

Metode pengambilan data dilakukan dengan beberapa tahapan yaitu diantaranya persiapan alat dan bahan, penyiapan rangkaian coil tembaga, penyiapan nitrogen cair, perekaman video hasil pengukuran, pengumpulan data dan analisis data. Dalam penelitian ini dibutuhan alat dan bahan penunjang untuk melakukan pengambilan data diantaranya yaitu: Multitester, Multimaster, Sumber tegangan, Nitrogen cair, Perekam, Termokopeel, Kabel penghubung, Coil tembaga, Tabung erlenmeyer, Gelas Ukur.

Setiap alat dan bahan yang disajikan memiliki peranan masing-masing. Rangkain pada gambar dihubungkan dengan lampu yang dapat berguna untuk mengamati secara kasap mata perubahan tegangan Keseluruhan alat tersebut dirangkai dalam gambar 1 berikut ini:

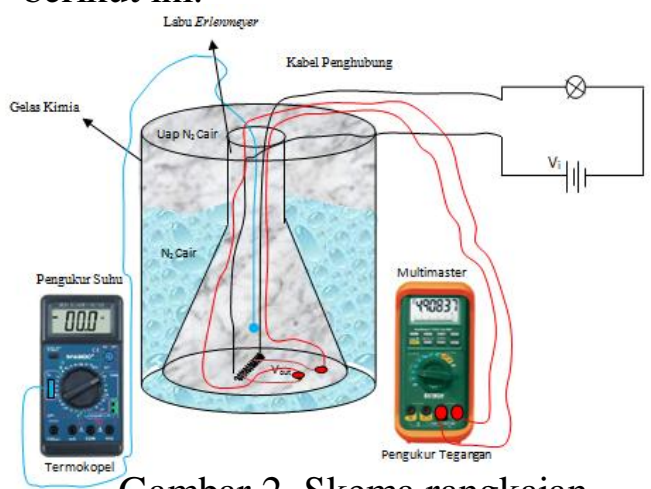

Gambar 2. Skema rangkaian 
Fungsi dari alat pada rangkaian gambar 2 meliputi multimaster (mengukur perubahan nilai hambatan coil tembaga) termokopel (menggukur perubahan suhu), Nitrogen cair (menghasilkan suhu lingkungan yang rendah), Coil tembaga (objek yang dipengaruhi oleh suhu). Coil tembaga dilakukan variasi 200 lilitan, 300 lilitan, 400 lilitan dan 500 lilitan dengan panjang kawat $l_{1}=350 \mathrm{~cm}, l_{2}=525 \mathrm{~cm}$ ,$l_{3}=700 \mathrm{~cm}$, dan $l_{4}=875 \mathrm{~cm}$ dengan diameter kawat yang digunakan 0,1 $\mathrm{mm}$.

Tahapan pengambilan data dalam penelitian ini dilakukan dengan langkah sebagai berikut: 1) Menghidupkan multimaster dengan selektor menunjukan pada skala ukur $m V$. 2) Menghidupkan termokopel. 3) Menghidupkan sakelar dengan tegangan input 3 volt (dilakukan pengukuran terlebih dahulu nilai tegangan). 4) Menghidupkan kamera laptop untuk merekam proses perubahan tegangan pada multimaster dan perubahan suhu pada termokopel. 5) Menuangkan Nitrogen cair ke dalam gelas kimia, mengamati perubahan suhu pada termokopel (suhu mencapai $\left.-130^{\circ} \mathrm{C}\right)$. 6) Mengelap embun pada diding kaca gelas kimia dan labu erlenmeyer yang berasal dari proses penguapan nitrogen cair. 7) Mengulangi langkah 1-6 untuk pengambilan data baru.

Untuk menentukan kurva hubungan antara tegangan dengan suhu udara karena pengaruh uap dari Nitrogen cair, digunakan pencocokan data (fitting data) polinomial orde dua,menurut (Bevington and Robinson, 1992:50).

$$
y(x)=a x^{2}+b x+c
$$

Pada persamaan 1, menjelaskan nilai koefisien a dan b mengandung variabel $x$ dinamakan slope, artinya menunjukan tingkat kemiringan kurva dan juga dapat digunakan untuk menentukan besar kecilnya nilai suatu fungsi. Sedangkan koefisien c dinamakan intercept merupakan titik perpotongan antara garis dengan sumbu y. Secara teoritis nilai c sebagai konstanta seharusnya bernilai nol, jika tidak sama dengan nol maka sesungguhnya terdapat ralat sistematis berupa zero 
offset baik yang bernilai positif atau bernilai negatif. Nilai $b$ positif menunjukan pengukuran terlalu besar dari yang seharusnya sedangkan nilai koefisien $b$ negatif menunjukan terlalu kecil dari yang seharusnya. Perhitungan nilai $\mathrm{a}, \mathrm{b}$ dan $\mathrm{c}$ dapat dilakukan analisis secara manual, namun dapat juga dilakukan dengan mnggunakan sofware ms excel menggunakan add trendline pada grafik yang telah dibuat.

Grafik hasil regresi dapat diuji kebaikan datanya dengan menggunakan chi square $\left(\chi_{v}^{2}\right)$ dan distribusi probabilitas $P_{x}\left(\chi_{v}^{2} ; v\right)$ yang masing-masing menggunakan persamaan.

$$
s_{y}=\sqrt{\frac{\sum\left(y-y_{e s t}\right)^{2}}{N-m}}
$$

(7)

$$
\chi_{v}^{2}=\frac{\chi^{2}}{v}
$$

$P_{x}(\chi ; v) \quad$ yang menyatakan

kebolehjadian pengamatan nilai $\chi^{2}$ dari hasil pengamatan dengan $N$ pengamatan dan $v$ derajat kebebasan. $\chi^{2}$ tereduksi/ termodifikasi menjadi $\chi_{v}{ }^{2}$ dengan $\mathrm{v}$ adalah derajat kebebasan (Taylor, 1997: 265).

$$
v=N_{\text {data }}-m
$$

$N$ adalah banyaknya data dan $m$ adalah parameter persamaan garis, pada persamaan garis polinomial orde dua $m=3$. Berdasarkan nilai chi square tereduksi $\left(\chi_{v}{ }^{2}\right)$, dapat ditentukan probabilitas $P_{x}\left(\chi_{v}^{2} ; v\right)$ data dengan melihat tabel hubungan $\left(\chi_{v}^{2}\right)$ terhadap distribusi $P_{x}\left(\chi_{v}^{2} ; v\right)$ menggunakan tabel C4 distribusi poisson. Kebaikan data dari hasil analisis yang dilakukan berdasar pada kajian Bevington and Robinson, menyatakan bahwa hasil fitting yang memuaskan secara operasional memiliki chi square tereduksi $\left(\chi_{v}^{2}\right)$ mendekati 1 dan memiliki distribusi probabilitas $P_{x}\left(\chi_{v}^{2} ; v\right)$ mendekati 0,5 .

\section{HASIL DAN PEMBAHASAN}

Sebelum dilakukan pengambilan data dilakukan uji pendahuluan untuk melihat kinerja alat terhadap respon perubahan suhu. Bentuk uji 
Riswanto- Analisis Resistansi Kawat Coil Tembaga...

pendahuluan dilakukan dengan perubahan tegangan coil tembaga menggunakan kawat panjang yang terhadap perubahan suhu. Pada dimasukan ke dalam air es. Aga lebih rangkaian dengan parameter diameter efektif kawat tembaga yang panjang kemudian dibuat menjadi lilitan (coil) dan dimasukan kembali ke dalam es diperoleh respon perubahan tegangan pada kawat. Hasil ini kemudian digunakan sebagai acuan untuk membuat kawat tembaga menjadi bentuk koil tembaga.

Pengambilan data dilakukan dengan merangkai alat dan bahan yang dibutuhkan sesuai dengan gambar 2. Perubahan resistansi pada coil tembaga diamati melalui pengukuran tegangan pada coil. Hal ini dilakukan karena besarnya nilai hambatan dalam sebuah rangkaian besarnya sebanding dengan tegangan atau beda potensial pada ujung-ujung rangkaian tersebut.Hasil dari pengolahan data yang telah dihimpun dari pengukuran yang terekam dalam video dilakukan plot untuk tiap kenaikan $2^{0} \mathrm{C}$ untuk diamati nilai resistansi kawatnya. Rekaman yang diperoleh diputar menggunakan sofware media player classic yang dengan pause menggunakan keyboard kawat tembaga $0,1 \mathrm{~mm}$ yang memvariasi panjang kawat menjadi $l_{1}=350 \mathrm{~cm}, l_{2}=525 \mathrm{~cm}, l_{3}=700 \mathrm{~cm}$, dan $l_{4}=875 \mathrm{~cm}$. Asumsi pemilihan panjang ini didasarkan pada jumlah lilitan yang dibentuk berturut-turut dihasilkan 200 lilitan, 300 lilitan, 400 lilitan dan 500 lilitan. Grafik data yang dihasilkan adalah sebagai berikut:

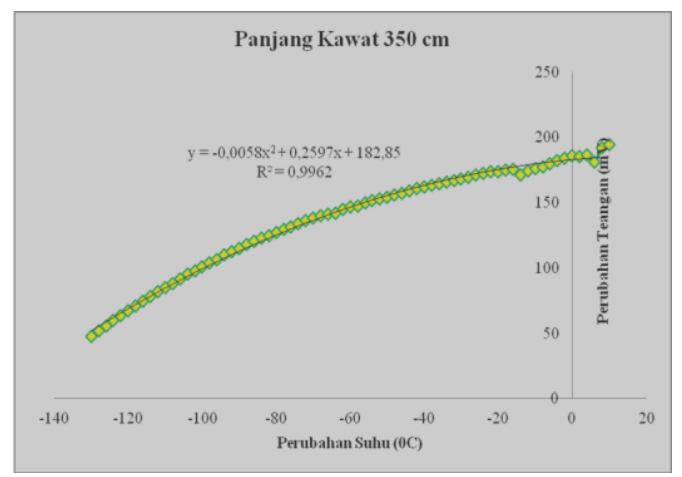

Gambar 3. Coil tembaga 200 lilitan

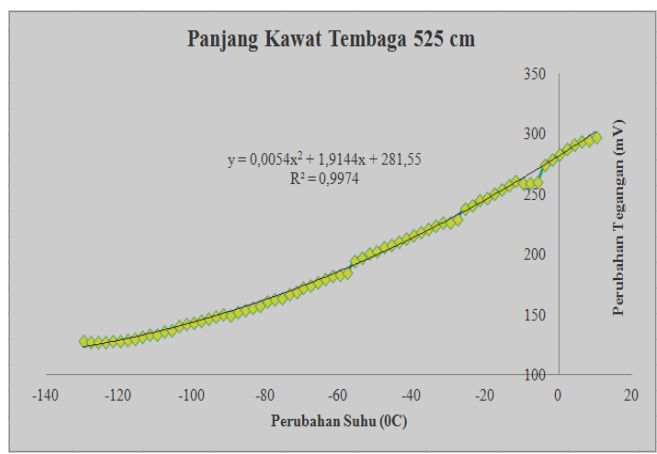

Gambar 4. Coil tembaga 300 lilitan spasi. Karakteristik hubungan 


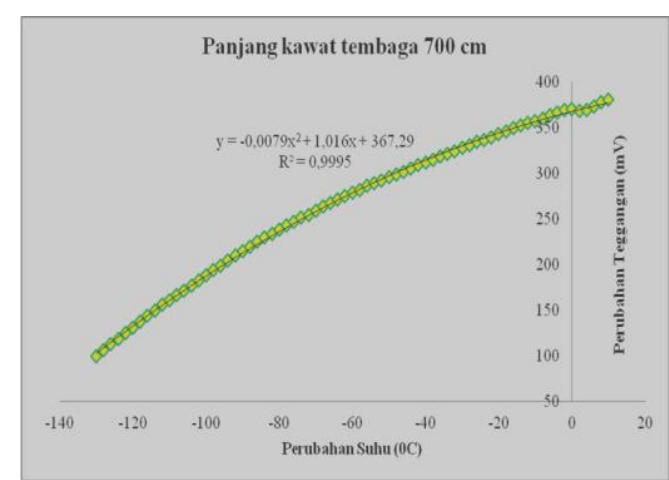

Gambar 5. Coil tembaga 400 lilitan

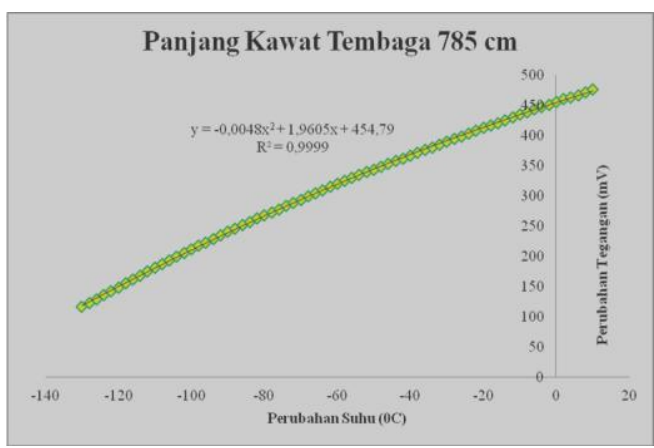

Gambar 6. Coil tembaga 500 lilitan

Pada grafik gambar 3 dan 5, slope bernilai negatif yang berarti grafik melengkung ke atas sedangkan gambar 4 slope bernilai positif yang berarti bahwa grafik melengkung ke bawah. Bentuk grafik yang melengkung memiliki tingkat linieritas yang kurang baik bila dibandingkan dengan grafik yang lurus. Linieritas menunjukan hubungan tingkat kesebandingan antara besaran suhu dengan besaran tegangan. Gambar 6 merupakan gambar yang memiliki tingkata linieritas yang terbaik dibandingkan dengan gambar-gambar yang lain.

Grafik yang terbentuk diperoleh melalui fitting data polinomial orde 2 bertujuan untuk memperoleh hubungan kenaikan perubahan suhu terhadap kenaikan perubahan tegangan pada masing-masing panjang kawat yang ditunjukan dalam tabel 1 berikut ini:

Tabel 1. Fungsi polinomial orde dua

\begin{tabular}{|c|c|c|c|}
\hline $\mathbf{i}$ & $\boldsymbol{l}(\mathbf{c m})$ & $\begin{array}{c}\text { Persamaan Polinomial orde } \\
\text { dua }\end{array}$ & $\boldsymbol{R}^{\mathbf{2}}$ \\
\hline 1 & 350 & $\begin{array}{c}y=-0,0058 x^{2}+0,2597 x+ \\
182,85\end{array}$ & 0,9962 \\
\hline 2 & 525 & $y=0,0054 x^{2}+1,9144 x+$ & 0,9974 \\
\hline 3 & 700 & $y=-0,0079 x^{2}+1,016 x+$ & 0,9995 \\
4 & 875 & $y=-0,0048 x^{2}+1,9605 x+$ & 0,9999 \\
\hline
\end{tabular}

Hasil tabel 1 menunjukan karakter bahwa berdasarkan hasil nilai indeks determinasi $\mathrm{R}^{2}$ yang diperoleh, terlihat secara keseluruhan variasi panjang kawat memiliki indeks determinasi yang mendekati angka 1. Pada coil dengan panjang $875 \mathrm{~cm}$ memiliki indeks determinasi paling baik $\left(\mathrm{R}^{2}=0,999\right)$ artinya bahwa perubahan suhu lingkungan direspon secara baik 
yang ditunjukan melalui respon perubahan tegangan.

Uji kebaikan dari hasil pencocokan data (fitting data) dapat ditentukan oleh indeks determinasinya, Kebaikan data dari hasil analisis fitting yang memuaskan secara operasional memiliki chi square tereduksi $\left(\chi_{v}{ }^{2}\right)$ yang mendekati 1 dan memiliki distribusi probabilitas $P_{x}\left(\chi_{v}{ }^{2} ; v\right)$ mendekati 0,5. Dengan hasil perhitungan teringkas pada tabel 2

Tabel 2. Hasil fitting data dari masingmasing diameter dan panjang kawat

\begin{tabular}{|c|c|c|c|c|c|}
\hline $\mathbf{i}$ & $\begin{array}{l}\text { Diamete } \\
\text { r (mm) }\end{array}$ & $\begin{array}{l}l \\
(\mathrm{~cm} \\
)\end{array}$ & $R^{2}$ & $\chi_{v}{ }^{2}$ & $P\left(\chi^{2} ; v\right)$ \\
\hline 1 & \multirow{4}{*}{0,1} & 350 & 0,996 & 1 & 0,4771 \\
\hline 2 & & 525 & 0,997 & 1 & 0,4771 \\
\hline 3 & & 700 & 0,999 & 1 & 0,4771 \\
\hline 4 & & 875 & 0,999 & 1 & 0,4771 \\
\hline
\end{tabular}

Guna melihat kepekaan respon perubahan suhu terhadap perubahan tegangan maka digunakan acuan time respond. Penetapan time respond merupakan selisih waktu yang dibutuhkan ketika suhu mengalami perubahan kenaikan dan sensor coil tembaga memberikan respon berupa kenaikan tegangan. Artinya jika suhu sudah mulai naik maka dikatakan memiliki time respond yang baik jika sensor langsung merespon dengan menunjukan perubahan tegangan. Hasil yang diperoleh bahwa coil tembaga merepon dengan cepat perubahan suhu lingkungan artinya ketika coil dimasukan dalam suhu lingkungan dingin nitrogen cair langsung terjadi perubahan tegangan yang terbaca pada multimaster.

Dari pola grafik memperlihatkan gambaran bahwa pengambilan data dimulai ketika suhu lingkungan terukur sebesar $-130^{\circ} \mathrm{C}$. Penyebaran pola mengikuti besarnya hambatan dari masing-masing kawat, semakin besar hambatan kawat maka tegangan output yang terbaca juga semakin besar. Asumsi peneliti bahwa semakin besar hambatan kawat akan memberikan respon terbaik terhadap perubahan suhu hal ini dapat terjadi karena ketika koil tembaga yang memiliki hambatan besar akan memiliki lebih banyak muatan yang bergetar. Banyaknya muatan ini akan megkontribusi terhadap banyaknya muatan yang merespon terhadap setiap perubahan suhu lingkungan disekitarnya. Sifat ini akan 
berbanding terbalik pada kondisi ketika koil tembaga memiliki nilai hambatan yang kecil.

Beberapa hal yang perlu diperhatikan diantaranya yaitu : a). pada bagian ujung-ujung koil tembaga perlu disambung dengan kabel agar ketika menjapit coil yang terlalu kecil tidak menyebabkan koil putus dan agar arus litrik dapat mengalir dengan baik. b). sifat nitrogen cair yang sifatnya mudah menguap, maka pengambilan data sebaiknya dilakukan pada malam hari ketika suhu dingin. c) setelah selesai melakukan pengambilan data maka embun yang ditimbulkan oleh nitrogen harus segera dilap dan dibersihkan, baru kemudian bisa melanjutkan pengambilan data kembali.

d). menghidupkan alat ukur ketika rangkaian telah terangkai dengan benar. e). Mengukur tegangan baterai sebelum dan sesudah digunakan dalam kegiatan eksperimen.

\section{PENUTUP}

\section{Kesimpulan}

Hasil penelitian diperoleh bahwa kawat tembaga yang dibentuk menjadi coil (lilitan) merupakan bentuk yang efektif yang dapat digunakan.
Kepekaan coil tembaga dalam merespon suhu yang teramati pada time respon menunjukan hasil yang baik, ketika coil dikenai perubahan suhu coil langsung merespon dengan perubahan tegangan. Hasil pengamatan dari grafik dan fitting data yang dilakukan menunjukan hubungan yang linier antara perubahan tegangan dengan perubahan suhu dengan nilai $\mathrm{R}^{2}=$ 0,999 artinya indeks determinasi yang mendekati nilai 1 pada kawat diameter 0,1 dan panjang $875 \mathrm{~m}$. Hasil ini menunjukan bahwa bentuk coil tembaga memiliki karakter yang baik untuk digunakan sebagai dasar sensor pengukuran suhu rendah.

\section{Saran}

Pengambilan data sebaiknya dilakukan pada lingkungan suhu yang dingin dalam ruangan berbantu AC agar suhu nitrogen cair tidak habis dengan cepat karena menguap.

\section{DAFTAR PUSTAKA}

Al-Hawari, T., Bool S., Al-Momani A. 2011. Selection of Temperature Measuring Sensors Using the Analytics Hierarchy Process, Jordan Journal Of Mechanical and Industrial Engineering Vol. 5 
Number 5, Irbid, Jordan University of Science and Technology.

Bevington, R. R.., \& Robinson, D. K. 1992. Data Rduction and Error Analysis for The Physical Sciences. Singapure: McGraw-Hill Book.

Galza, G, L.M Gratton, T. Lopez-Arias. 2011. very fast temperatur measurement with a thin lamp filament. Journal physics education, iopscience.org/physed

Giancolli, 2001. Physics Fifth Edition. Alih bahasa Hanum, Yuhilza. 1998. Fisika Edisi Ke Lima jilid 2. Jakarta: Erlangga

Meyers. C.H. Coiled Filament Thermometer. NBS. Journal of Research, Vol 9. Th 1932.

Muslim dan Zahara, M. 2004. Seri Fisika Dasar Listrik Dinamik dan Magnet Statik: Medan, Sumber dan Medium. Yogyakarta: Prodi Fisika FMIPA Universitas Gajah Mada.

Taylor, J. R. (1997). An Introduction to Error Analysis : The Study of Uncertainties in Physical Measurements. Sausalito, California: University Science Books

Young, H.D. dan Freedman, R.A. 2001. University Physics Tent Edition. Alih bahasa Siahaan, Pantur. 1996. Fisika Universitas edisi sepuluh jilid 2. Jakarta: Erlangga. 